\title{
Biodiversity protection and ecological restoration of Guilin Karst quarry
}

\author{
Ziliu Qin ${ }^{l}$, Qiutong Chen ${ }^{l}$, Xiang $J^{l}$, Shuang Ming ${ }^{l}$, and Qin Du ${ }^{1, *}$ \\ ${ }^{1}$ College of Tourism\&Landscape Architecture, Guilin University of Technology, Guilin 541006, China
}

\begin{abstract}
The abandoned quarry as a witness left by industrial history has greatly damaged the mining area and the surrounding ecological environment, causing severe disturbances on the surface, soil erosion and biodiversity decline. Therefore, the ecological restoration of abandoned quarries has become an important focus of ecological restoration. This article summarizes the current situation and distribution characteristics of Guilin karst quarry, and analyses the current problems of ecological restoration in karst quarry. Accordingly, it is proposed that the ecological restoration of the Guilin Karst quarry should focus on the reconstruction of the mining area ecosystem and the protection of biodiversity, and accordingly proposed corresponding restoration proposals.
\end{abstract}

\section{Introduction}

Modern urban construction needs a lot of stone resources, and karst landform is mainly composed of limestone, which is one of the main building stones ${ }^{[1]}$. As an important means for human to obtain stone resources, quarrying plays an important role in promoting the process of urbanization. However, it also leads to a large number of quarries plundering land resources and leaving a large number of abandoned quarries after the end of quarrying activities. According to statistics, Guilin now has 506 mineral lands of various types, more than 200 quarries alone. A large number of quarries have damaged the soil and rock structure of the land, causing serious water and soil loss in the mining area. At the same time, it will also cause serious damage to vegetation and animal habitat, and the decline of biodiversity, which greatly threatens the protection of wild animal and plant communities. Therefore, quarrying is generally considered as an industrial behaviour that seriously damages the nature ${ }^{[2]}$.

In recent years, Guilin city has paid more and more attention to the protection and restoration of karst ecological environment. In 2016, Guilin City closed the quarries in Lijiang nature reserve and made ecological restoration. In 2017, the government issued the 13th five year plan for environmental protection of Guilin City, which emphasizes seven aspects of ecological environment protection, including strengthening biodiversity protection and strengthening the restoration and management of degraded ecosystem, hoping to change the continuous deterioration of karst ecological environment, build a resource-saving and environmentfriendly society, and improve the level of ecological civilization .

\section{Characteristics of Guilin Karst quarry}

According to the visual interpretation of satellite remote sensing image and field survey, 288 quarry pits are found in Guilin City, which are distributed in 11 counties and 5 municipal districts (Figure 1), with a total area of $30.31 \mathrm{~km}^{2}$ (Table 1). The main features are as follows.

\subsection{Concentrated in low altitude and high dense population areas}

Viewed as a whole, the distribution of quarries in Guilin City is very uneven, showing a large aggregate and small scattered distribution pattern. Most of the quarries are concentrated in densely populated areas south of central Guilin, forming several important core distribution areas. Among them, Lingui District is the core point, the quarries around Guilin and Lingchuan County are the main distribution areas, and the other core distribution areas are the core distribution area of Yangshuo County, the core distribution acrea of Lipu County, and the core distribution area of Quanzhou County. Viewed from the local area, these quarries are relatively dispersed. The quarries in the densely distributed areas are relatively independent and separated by a long distance. Only a few quarries are connected to each other.

\subsection{The spatial form is similar and the scale is generally small}

All kinds of pits will be formed in the quarry after intense quarrying activities. However, due to the special karst terrain, most of them are single peaks, and the mountain is also relatively steep, so the mining method

\footnotetext{
* Corresponding author: 80168391@.qq.com
} 
of Guilin Karst rock mountain is relatively single, so it is impossible to carry out large-scale mining activities. Therefore, although the shapes and sizes of Guilin Karst quarries are not nearly the same, they are also different, but they are similar in space form. The main space is fan-shaped cliff platform space and semi open cliff platform space, and the few are partition type cliff space and open platform space. Most of the quarries are small in area, and the surface area of the smallest quarry is only $0.038 \mathrm{~km}^{2}$, and the average area is less than 0.105 $\mathrm{km}^{2}$.

\subsection{Rich landscape types and complex spatial structure}

The interference of quarrying will bring great changes to the structure of the mountain, which makes the interior of the quarry form complex and changeable landscape types ${ }^{[3]}$. First of all, mining will make the mountain form one or several huge cliffs, close to the vertical exposed cliff and form a strong visual impact compared with the surrounding environment; second, quarrying activities will leave a relatively flat and open operation platform, with a large number of waste stones left inside the platform. After the stacking of stones and rain washing, uneven and complex structures are formed Landscape space, a small number of quarries will form a large deep pit, evolved into a pool. Therefore, cliffs, slope platforms, gravel gullies, water pools and depressions have become the main landscape types of karst quarries. Different quarries have different combinations of landscape types. These types are changeable and complex, which make the original site landscape no longer exist, but increase the heterogeneity and diversity of the internal landscape space.

Table 1. Distribution of quarries in Guilin.

\begin{tabular}{|c|c|c|c|}
\hline $\begin{array}{c}\text { Guilin } \\
\text { municipal } \\
\text { district }\end{array}$ & $\begin{array}{c}\text { Number of } \\
\text { quarries }\end{array}$ & $\begin{array}{c}\text { Total area } \\
\mathbf{~ k m}^{\mathbf{2}}\end{array}$ & $\begin{array}{c}\text { Average area } \\
\mathbf{~ k m}^{\mathbf{2}}\end{array}$ \\
\hline Yangshuo & 36 & 0.564 & 0.051 \\
\hline Lingchuan & 38 & 7.495 & 0.197 \\
\hline Lingui & 31 & 3.465 & 0.111 \\
\hline Quanzhou & 36 & 2.180 & 0.060 \\
\hline Xingan & 23 & 3.212 & 0.140 \\
\hline Yongfu & 2 & 0.385 & 0.192 \\
\hline Longsheng & 7 & 2.110 & 0.301 \\
\hline Guanyang & 18 & 1.380 & 0.076 \\
\hline Gongcheng & 16 & 3.933 & 0.245 \\
\hline Pingle & 23 & 1.290 & 0.056 \\
\hline Lipu & 32 & 2.060 & 0.064 \\
\hline Ziyuan & 14 & 0.872 & 0.062 \\
\hline Total & 288 & 30.310 & 0.105 \\
\hline
\end{tabular}

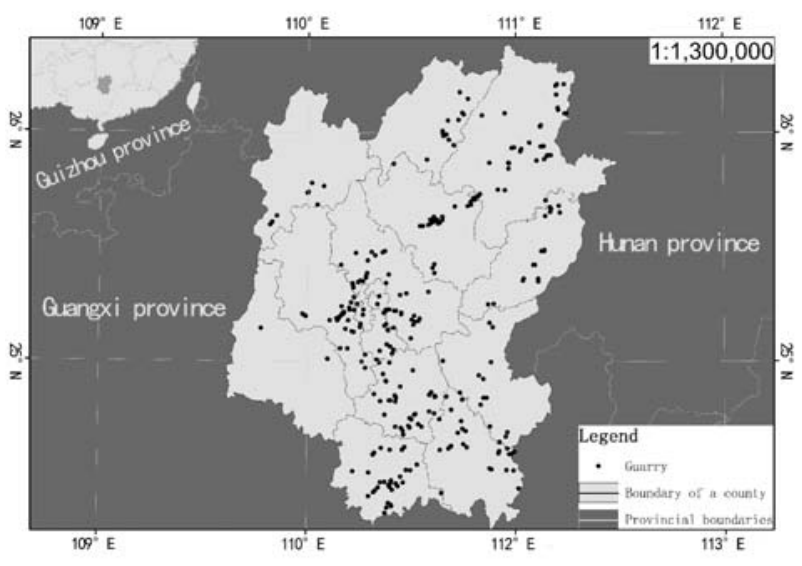

Fig. 1. Distribution of quarries in Guilin.

\section{Biodiversity protection and ecological restoration of quarries.}

\subsection{Single vegetation and low plant diversity}

Revegetation of quarry vegetation is the main way of ecological restoration, especially the restoration of structural diversity of vegetation community can effectively improve the diversity of animal community, improve the quality of habitat, and build a relatively complete biological chain, so as to promote the restoration of quarry ecosystem ${ }^{[4]}$. In Guilin Karst quarry, Pinus massoniana and c are selected as the main trees and shrubs, while the vines are mainly Tokyo silverback vines. Although the selected restoration plants are all local species, which can grow in bad habitats, but there are few species, and a single plant species is planted in a large range, ignoring the diversity and richness of community structure, which is not conducive to the improvement of the habitat quality of quarrying wasteland.

\subsection{Land levelling loses spatial heterogeneity}

Complex and diverse space can provide a good habitat for animal and plant communities ${ }^{[5]}$. Research shows that the diversity of spatial structure is often more than the biodiversity of a single type of space. However, in the process of ecological restoration and land reclamation of the quarry, a large area of plant planting needs open space, so all kinds of gravel piles in the quarry will be cleaned up, and the gullies formed by mining will be backfilled. Although the land levelling can cover the traces of Quarrying and make it more integrated into the surrounding environment, it can destroy the remaining topography and landscape resources, lose the heterogeneity of the original habitat space, and is not conducive to improving the diversity of animal and plant communities.

3.3 Pay too much attention to artificial restoration and neglect the role of natural succession 
At present, the practice of ecological restoration of quarries mainly focuses on artificial restoration, staying at the level of vegetation restoration, and using engineering technology to reclaim land and plant in abandoned quarries. Although the speed of restoration is faster than that of natural succession, the quality of restoration, especially the biodiversity, is far lower than that of quarries after decades of natural restoration. This is because the landscape space and plant community formed by natural succession are more abundant than the single vegetation and monotonous structure space of artificial restoration quarry, which can effectively improve the quality of abandoned quarry as the habitat of wild animals and plants.

\section{Biodiversity protection and ecological restoration of quarries.}

According to the definition of biodiversity in the National Biodiversity Assessment of the United Nations Environment Programme, biodiversity is the overall diversity and variability of organisms and their systems. Therefore, biodiversity not only refers to species diversity, but also includes genetic diversity and ecosystem diversity. Among them, the diversity of ecosystem has a profound impact on species diversity. First of all, the diversity of ecosystem is the basis of species diversity. The more perfect the ecosystem function, the richer its structure, the more diversity of its species. Secondly, species diversity is the reflection of ecosystem diversity. In a certain region, if the number of species is more, the diversity is more abundant, indicating that the quality of ecosystem in the region is higher. Therefore, the protection of biodiversity not only lies in the protection of species themselves, but also needs to pay attention to the ecological environment on which organisms live.

The purpose of ecological restoration of Guilin Karst quarry is to solve the existing problems of mine geological environment and a series of possible problems of mine ecological environment caused by subsequent mining activities, so as to realize the gradual restoration of mine ecological system. Biodiversity is not only an important indicator to measure the quality of mine restoration, but also an important part of the ecosystem, which directly reflects the success of restoration measures. Compared with the study of biodiversity conservation on the scale of land spatial planning, the study of the impact of ecological restoration of quarry wasteland on biodiversity focuses on how to use and improve the living space of species in small-scale space, especially in "brown land" type land, so as to protect biodiversity.

\section{Advise}

\subsection{Construction of a multi-mode hierarchical recovery mechanism for Karst quarrying wasteland}

At present, the restoration of Guilin karst quarry wasteland mainly adopts manual restoration, and no corresponding adjustments have been made according to its geographical location, site status and ecologically sensitive areas, resulting in high initial restoration costs and insufficient results. Therefore, the ecological restoration of abandoned karst quarries should be adapted to local conditions, and a multi-model hierarchical restoration mechanism should be constructed. When constructing the mechanism, the following steps should be followed. 1) Evaluate the ecological sensitivity of Guilin on the spatial scale. Taking Guilin's land use type, normalized vegetation coverage index (NDVI), soil erosion, water buffer, and annual average rainfall as single factor factors, using GIS geographic analysis software to carry out sensitivity analysis and mapping, and divide ecological sensitivity There are four ecologically sensitive areas: low sensitive area, medium sensitive area, high sensitive area and extremely sensitive area. 2) Establish priority restoration grades based on ecologically sensitive areas. First, priority should be given to repairing quarries in extremely sensitive areas. Finally, gradually repair the abandoned quarry site with high sensitivity. For the quarries in the middle and low sensitive areas, there is no need to deliberately repair, but it is necessary to regularly monitor the gradually restored animal and plant communities in the mining area. 3) Different repair modes are adopted according to the different sensitive areas where the abandoned site of the quarry is located. In the extremely sensitive area, the quarry wasteland should adopt strong manual intervention measures to speed up the repair of the mining area. For the abandoned areas of quarries in high-sensitivity areas, remediation measures that co-exist with human intervention and natural remediation are taken. Finally, for the quarry wasteland in the middle or low sensitive area, the natural recovery mode is mainly adopted, without any artificial intervention measures, and only relying on the rich vegetation resources and seed banks around the mining area to gradually restore the ecological environment of the mining area, thereby constructing an ecosystem with rich biological communities and well-structured.

\subsection{Study on the natural succession process of karst quarrying wasteland}

The natural succession process is the basis of the theory of ecological restoration of quarries. Understanding the natural succession mode of karst quarrying wasteland can provide theoretical basis for ecological restoration, so as to better guide ecological restoration ${ }^{[6]}$. In the process of exploring the natural succession model of karst quarrying wasteland, the following points should be paid attention to. 1) To explore the limiting factors and their influence on the natural recovery of karst quarries. The recovery of karst quarry ecosystem is limited by many factors, including biological and abiotic factors. AHP is used to build the hierarchy model and judgment matrix, and the main restrictive factors are 
evaluated comprehensively to explore which factors are the key factors in the process of natural recovery of quarry habitat. 2) Evaluate the influence of different interference factors on natural recovery process. Interference can promote or slow down the process of natural succession of quarries, and the occurrence of interference has a lot of accidental factors. To predict the process of natural succession of quarries, it is necessary to evaluate the impact of different forms of interference factors on quarries, and at the same time try to avoid the occurrence of human interference factors. 3) To evaluate the habitat quality of quarries in different periods under natural recovery. The natural succession process of quarry is very slow, which is a long-term evolution process. At the same time, the animal and plant communities formed in the early and later stages of succession are quite different, so it is necessary to scientifically evaluate the habitat quality of quarries in different periods. The evaluation includes the analysis of the content of pollutants, soil organic matter, topography and geomorphology, the composition and diversity of animal and plant communities in the quarry.

\subsection{Establish a mine park focusing on geological science popularization and Biological Conservation}

Reconstruction and design of the quarry wasteland as park green space is an important means of ecological restoration, which can effectively reuse the unique landscape resources and landscape recreation function in the mining area ${ }^{[7]}$. The karst quarry in Guilin is rich in landscape resources and has the potential to be developed into an urban park. In the planning and design of urban mining parks, first of all, according to the geographical location and industrial nature of the site, the characteristics of karst geological landforms and industrial legacy should be highlighted on the theme, and geological science education should be carried out. Secondly, the design should follow the minimalist style. In addition to the necessary service facilities, large-scale renovation of the site should be avoided, and new largescale facility buildings should be avoided. Finally, in the selection and planting of plants, it is necessary to consider not only native tree species but also plant diversity, but large-scale singular planting models should be avoided. When planting plants, the potential of the topography and landforms left by quarrying activities can be fully utilized to form a complex habitat. It is appropriate to cover the soil in a small area and spread a small number of grass species to promote the restoration of vegetation.

\section{Peroration}

The existence of the quarry greatly damaged the ecosystem of the Karst area and reduced biodiversity, making it a scar that is difficult to repair. Therefore, the ecological restoration in the quarry should focus on ecosystem reconstruction and biodiversity protection, adopt a multi-model hierarchical recovery mechanism, pay attention to the natural recovery ability, and explore the ability of the quarry ecosystem to repair itself under the natural recovery model, so the natural restoration of the quarry becomes the main restoration method. At the same time, certain manual interventions are necessary, especially in sensitive areas. Due to the lack of sufficient capacity to resist the ecological risks from abandoned quarries, natural restoration obviously cannot quickly and effectively reduce the impact on the surrounding environment and the risk of the quarry itself. Therefore, natural restoration should be the main part of karst ecological restoration, supplemented by manual intervention, so as to promote the karst quarry ecological restoration and biodiversity protection in a more scientific and reasonable direction.

\section{Acknowledgement}

We thank the Natural Science Foundation of Guangxi Province(2018GXNSFAA050068, 2018JJB130217) and Major projects of Guilin Science and Technology Development (20180102-2) for funding support.

\section{References}

1. T. Darwish, C. Khater, I. Jomaa, R. Stehouwer. Environmental impact of quarries on natural resources in Lebanonl[J]. Land degradation \& development, 2011(22): 345-358

2. T. Milgrom. Environmental aspects of rehabilitating abandoned quarries: Israel as a case study[J]. Landscape and Urban Planning, 2008,87 (3) :172179

3. G. J. Gao, J. G. Yuan, R. H. Han. Characteristics of the optimum combination of synthetic soils by plant and soil properties used for rock slope restoration[J] .Ecological Engineering,2007,30(4) : 303-311

4. R. Gentili, S. Sgorbati, C. Baroni. Plant Species Patterns and Restoration Perspectives in the Highly Disturbed Environment of the Carrara Marble Quarries (Apuan Alps, Italy) [J]. Restoration Ecology,2011, 101(19) :32-42

5. F.Bétard. Patch-Scale Relationships Between Geodiversity and Biodiversity in Hard Rock Quarries: Case Study from a Disused Quartzite Quarry in NW France[J]. Geoheritage, 2013(5): 5971

6. Z. Y. Yuang, L. Xue, J. X. Xu. Advances in ecology restoration of abandoned quarries[J]. Acta Ecologica Sinica, 2012,32(16): 5264-5274

7. G. Guler, A. C. Yildizci. From quarry to urban park. Giving new life to the Eyup quarry in Istanbul[J]. Journal of Environmental Protection and Ecology,2010,11(4) : 1408-1416 